\title{
Sting to the Heart - Acute Pulmonary Edema following Hymenoptera Sting
}

\author{
Jijin Satheesh, Deepak Rajkumar Vangipuram, M. Rajkumar \\ Department of General Medicine, Sri Ramachandra Medical College, Chennai, Tamil Nadu, India
}

\section{Abstract}

Hymenoptera stings have been reported earlier to cause mild local reactions to severe systemic reactions such as anaphylactic shock. Myocardial infarction following insect stings has been widely described. In this case, we describe a 64-year-old male patient who presented with pulmonary edema $4 \mathrm{~h}$ after the initial insult followed by a new onset myocardial infarction which was considered to be a variant of Kounis syndrome. The patient was managed in intensive care with diuretics, positive pressure ventilation, and glucocorticoids and made a complete recovery.

Keywords: Acute coronary syndrome, hymenoptera sting, Kounis syndrome, pulmonary edema

\section{INTRODUCTION}

Hymenoptera stings are encountered usually in rural settings but are being increasingly encountered in urban settings as well. Hence, the need to recognize the various disease processes seen with this. An increasing number of patients are seen presenting to the emergency department with minor local reactions to serious problems such as anaphylactic shock and even fatal myocardial infarction. It is important to appropriately manage these patients at the first point of medical care and to anticipate the inherent and often delayed complications associated with stings. We present a case where pulmonary edema developed $4 \mathrm{~h}$ after the initial insult and intensive management with a multispecialty care helped avoid mortality.

\section{Case Report}

A 64-year-old male patient presented to our casualty services with a history of multiple bee stings while traveling on a bike. He had stings all over the body predominantly to his arms, chest, and face. The patient developed pain followed by mild swelling at the site of stings, however was otherwise asymptomatic. He consulted a nearby clinic where the embedded stingers were removed, vitals monitored, and he was discharged after prophylactic treatment with pheniramine and hydrocortisone. The patient continued his travel home but noticed that he was gradually becoming breathless progressing on to severe

\begin{tabular}{|l|l|}
\hline \multicolumn{2}{|c|}{ Access this article online } \\
\hline Quick Response Code: & Website: \\
& www.ijrconline.org \\
\cline { 2 - 2 } & \\
\end{tabular}

breathlessness at rest. He was then brought to our institute by his son.

On clinical examination, the patient presented with tachypnea, room air oxygen saturation of $85 \%$, tachycardia, blood pressure of 140/90 $\mathrm{mmHg}$, elevated jugular venous pressure, S3 gallop on cardiac auscultation, and bilateral coarse crepitations in the lower lung fields. He was shifted to the Intensive Care Unit (ICU) for further evaluation and management.

History revealed that he was a known case of coronary artery disease having suffered from an anteroseptal myocardial infarction 4 years ago. Echocardiogram then had shown left ventricular (LV) systolic dysfunction and ejection fraction of $45 \%$.

In the ICU, baseline investigations were obtained which showed an elevated creatinine, neutrophilic leukocytosis, elevated brain natriuretic peptide, normal troponin I, elevated creatinine kinase, and serum IgE levels. Initial electrocardiogram (ECG) showed sinus tachycardia with QS complexes in anteroseptal leads, but serial ECG monitoring was done at $6 \mathrm{~h}, 12 \mathrm{~h}$, and $24 \mathrm{~h}$ which showed new onset, progressive $\mathrm{T}$ inversions in

Address for correspondence: Dr. Jijin Satheesh, Department of General Medicine, Sri Ramachandra Medical College, Porur, Chennai, Tamil Nadu, India. E-mail: jijin_0511@yahoo.com

This is an open access article distributed under the terms of the Creative Commons Attribution-NonCommercial-ShareAlike 3.0 License, which allows others to remix, tweak, and build upon the work non-commercially, as long as the author is credited and the new creations are licensed under the identical terms.

For reprints contact: reprints@medknow.com

How to cite this article: Satheesh J, Vangipuram DR, Rajkumar M. Sting to the heart - Acute pulmonary edema following hymenoptera sting. Indian J Respir Care 2018;7:56-8. 
Satheesh, et al.: Acute Pulmonary Edema following Hymenoptera sting

leads V5, V6, I, and avL. Troponin T was done and showed significant positive titers which peaked within $48 \mathrm{~h}$ suggestive of a new onset myocardial infarction. Chest X-ray [Figure 1] showed bilateral diffuse infiltrates involving the middle and lower zones of the lungs. A two-dimensional echocardiogram showed dilated left ventricle, entire anteroseptum, anterior wall, apical inferior wall, entire inferoseptum thinned out and severely hypokinetic with systolic dysfunction, and ejection fraction of $41 \%$. Computed tomography thorax [Figure 2] showed confluent widespread areas of consolidation and ground glass opacities with interlobular septal thickening seen in bilateral lung fields. The patient was treated with furosemide infusion, positive pressure ventilation, enoxaparin, dual antiplatelet therapy, statins, and intravenous hydrocortisone. Coronary angiogram was planned but could not be done due to high risk of worsening renal failure. The patient improved clinically over the course of 5 days with lung signs decreasing, and chest X-ray [Figure 3] showed clearing of infiltrates. He was discharged on the $10^{\text {th }}$ day postillness.

\section{Discussion}

Insect stings from bees, wasps, hornets, and other Hymenoptera insects have been classically associated with many forms of reaction. While most people may have a limited cutaneous reaction, severe forms of systemic disease usually manifest as anaphylactic reactions, gastrointestinal disturbances, respiratory compromise, and cardiovascular collapse. ${ }^{[1]}$

Death from cardiovascular complications is compounded by the presence of preexisting atheromatous lesion in the coronaries. ${ }^{[2,3]}$ Biló et al. described the following risk factors to determine severity of reaction: short interval between stings, frequency of stings, venom sensitization, severity of preceding disease, elderly age groups, cardiovascular disease and use of beta-blockers, bee stings, and elevated serum tryptase levels/mastocytosis all predispose to a more severe disease. ${ }^{[4]}$

Kounis syndrome is an entity described by Kounis and Zavras in 1991 as the concurrence of acute coronary syndromes such as coronary spasm, acute myocardial infarction, and stent thrombosis, with conditions associated with mast cell and platelet activation involving interrelated and interacting inflammatory cells in the setting of allergic or hypersensitivity and anaphylactic or anaphylactoid insults. ${ }^{[5]}$ Three variants have been described: the Type I variant includes normal or nearly normal coronary arteries without risk factors for coronary artery disease, the Type II variant includes culprit but quiescent preexisting atheromatous disease in which the acute release of inflammatory mediators may induce either coronary artery spasm with normal cardiac enzymes and troponins or coronary artery spasm together with plaque erosion or rupture manifesting as acute myocardial infarction, the Type III variant includes coronary artery stent thrombosis in which aspirated thrombus specimens stained with $\mathrm{H}$ and $\mathrm{E}$ and Giemsa demonstrate the presence of eosinophils and mast cells, respectively. ${ }^{[6]}$ Our patient can be considered to have

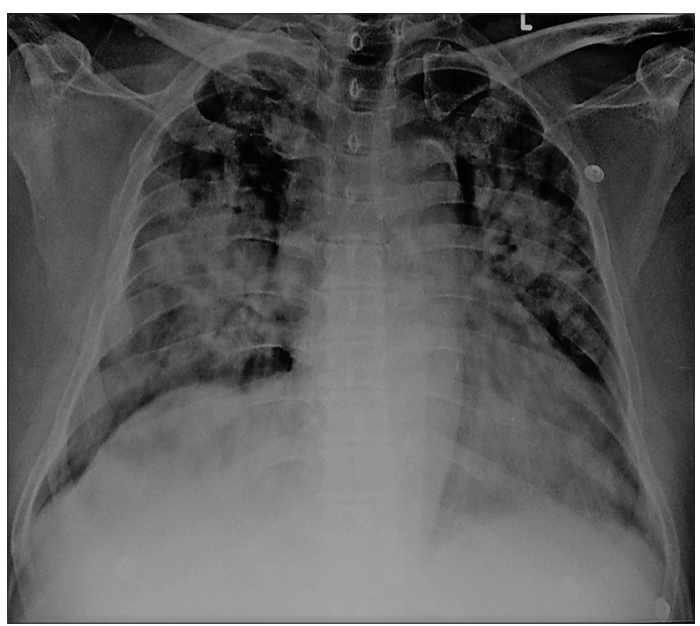

Figure 1: Chest $X$-ray showed diffuse infiltrates in bilateral lungs involving the middle and lower zones

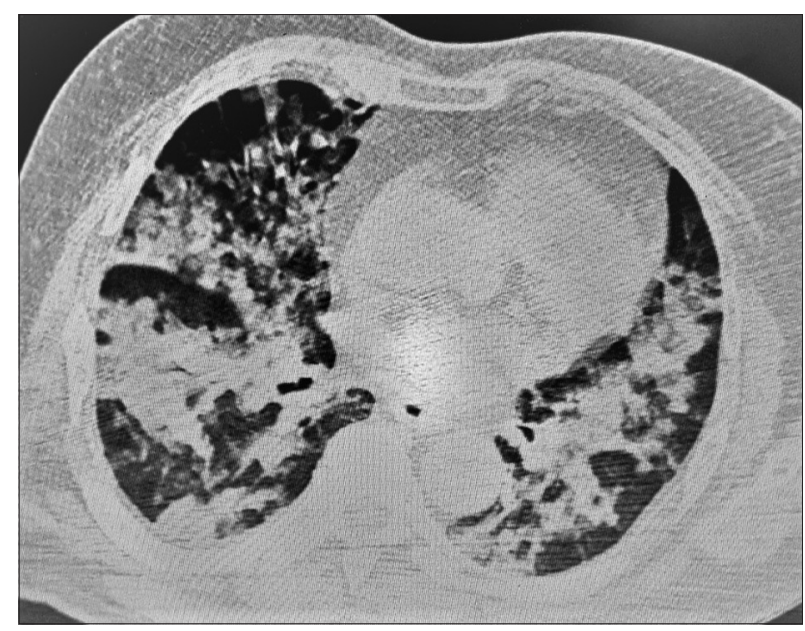

Figure 2: Computed tomography thorax done showed confluent widespread areas of consolidation and ground glass opacities with interlobular septal thickening seen in bilateral lung fields

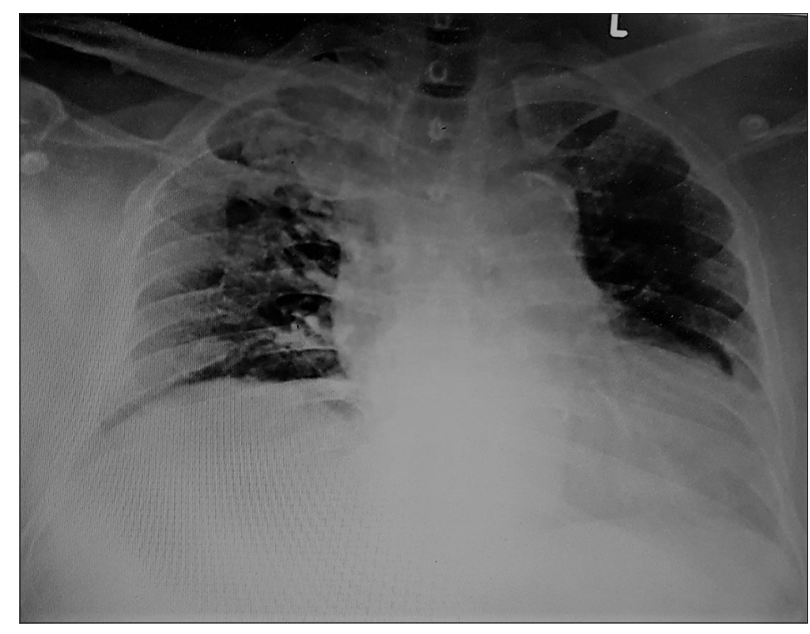

Figure 3: Chest X-ray showed clearing of infiltrates

Type 2 disease, but an angiogram needed to prove it could not be obtained due to high risk of worsening renal failure. 


\section{Satheesh, et al.: Acute Pulmonary Edema following Hymenoptera sting}

Interestingly, this patient developed pulmonary edema well before the onset of myocardial infarction possibly because of the preexisting coronary artery disease with LV systolic and diastolic dysfunction. Treatment protocols should follow that of acute coronary syndrome and pulmonary edema with superadded cover of glucocorticoids and H1-antihistamines to ameliorate the effect of IgE-mediated reactions. The purpose of this case report is to highlight the delayed presentation of life-threatening cardiovascular and respiratory compromise following a Hymenoptera sting and that it may be advisable to monitor them at a hospital at least for $24 \mathrm{~h}$. Medical professionals need to be well aware of the possible complications and manage them appropriately.

\section{Acknowledgment}

I would like to thank my professor Dr. M Rajkumar and my assistant Dr. Vangipuram Deepak Rajkumar for their active contribution toward this case report. I also extend my wholehearted gratitude to the cardiology department whole active role played a favorable outcome in the patient's prognosis. And most importantly, my deepest thanks to the patient for his cooperation that fulfilled our goal toward furthering education and knowledge.

\section{Declaration of patient consent}

The authors certify that they have obtained all appropriate patient consent forms. In the form the patient(s) has/have given his/her/their consent for his/her/their images and other clinical information to be reported in the journal. The patients understand that their names and initials will not be published and due efforts will be made to conceal their identity, but anonymity cannot be guaranteed.

\section{Financial support and sponsorship}

Nil.

\section{Conflicts of interest}

There are no conflicts of interest.

\section{RefEREnCes}

1. Mueller HL. Diagnosis and treatment of insect sensitivity. J Asthma Res 1966;3:331-3.

2. Sasvary T, Müller U. Fatalities from insect stings in Switzerland 1978 to 1987. Schweiz Med Wochenschr 1994;124:1887-94.

3. Mosbech H. Death caused by wasp and bee stings in Denmark 1960-1980. Allergy 1983;38:195-200.

4. Biló BM, Rueff F, Mosbech H, Bonifazi F, Oude-Elberink JN, EAACI Interest Group on Insect Venom Hypersensitivity. Diagnosis of hymenoptera venom allergy. Allergy 2005;60:1339-49.

5. Kounis NG, Zavras GM. Histamine-induced coronary artery spasm: The concept of allergic angina. Br J Clin Pract 1991;45:121-8.

6. Kounis NG, Mazarakis A, Tsigkas G, Giannopoulos S, Goudevenos J. Kounis syndrome: A new twist on an old disease. Future Cardiol 2011;7:805-24. 